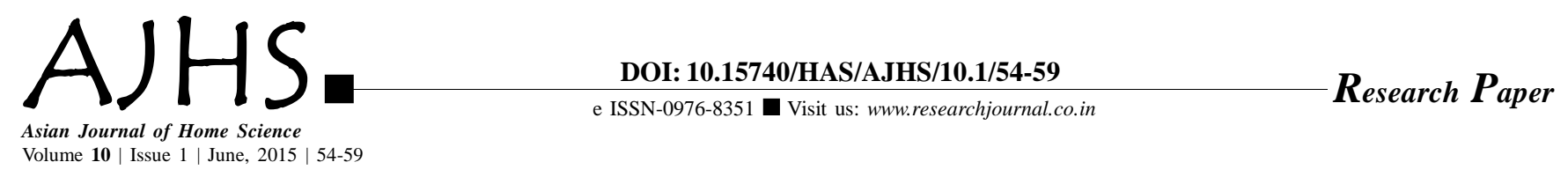

\title{
Traditional costumes of women from Bohra community in Udaipur, Rajasthan
}

\author{
SHRUTI RAWAT AND RUPAL BABEL
}

Received: 17.06.2014; Revised: 21.03.2015; Accepted: 25.03 .2015

See end of the paper for authors' affiliations SHRUTI RAWAT

Department of Textiles and Apparel Designing, College of Home Science, Maharana Pratap University of Agriculture and Technology, UDAIPUR (RAJASTHAN) INDIA

Email : 05shrutirawat@gmail.com
ABSTRACT : Clothing is a representation of cultures and beliefs. They portray an identity and conform to a social group. The styles uphold varies from castes to tribes and religions. In Islam, women conceal their bodies and wear a 'hijab' or veil called 'burqa'. They believe that adherence to hijab is a manifestation for chastity and modesty. The burqa comes in various styles and varies from country to country. The one worn by the Bohras is completely different from the ones worn by the other Muslim communities as these are rather colourful than black. Besides covering oneself, they comparatively enjoy greater access to colours and designs.

KEY WORDS: Traditional costumes, Women, Bohra community

- HOW TO CITE THIS PAPER : Rawat, Shruti and Babel, Rupal (2015). Traditional costumes of women from Bohra community in Udaipur, Rajasthan. Asian J. Home Sci., 10 (1) : 54-59. 